\title{
Pedagogical Synergy: Linking Assessment, Curriculum, and Instruction
}

\author{
Drs. Blair Mascall and Carol Rolheiser \\ Ontario Institute for Studies in Education, \\ University of Toronto
}

\begin{abstract}
This paper describes the evolution of attempts to build coherence and capacity in an Ontario school district, focusing on the development of literacy strategies in all of the district's elementary and secondary schools. In reviewing case studies in four elementary schools, the authors have identified three key elements (instruction, curriculum, and assessment) as the key dimensions which have the greatest influence on student achievement. The authors of this paper present a new construct, pedagogical synergy, in which those three elements are combined. Improvements can occur at both the district and school levels when there are horizontal and reciprocal strategies for building capacity and increasing coherence. It is the mutual support between district and schools that provides the power in this new concept.
\end{abstract}

\section{Introduction}

When we started our research in the York Region District School Board (YRDSB) in 1999, we were exploring the development of capacity in the implementation of an early literacy pilot program. We use the term capacity in this paper to describe the knowledge and skills of individuals or groups. We used a conceptual framework by Newmann, King and Youngs (2000) which described the relationship between government or district policies and programs and student 
achievement, by identifying two key variables: instructional quality, (which is the major determinant of student achievement), and school capacity, which the authors postulated was the determinant of instructional quality (see Figure 1). We found this a helpful model as we focused on important dimensions of school capacity. Our subsequent research has moved us beyond that model, to conceptualizing a model of district capacity. We often return to the Newmann, King and Youngs research, however, as a foundational piece in our understanding of collective capacity at the school level.

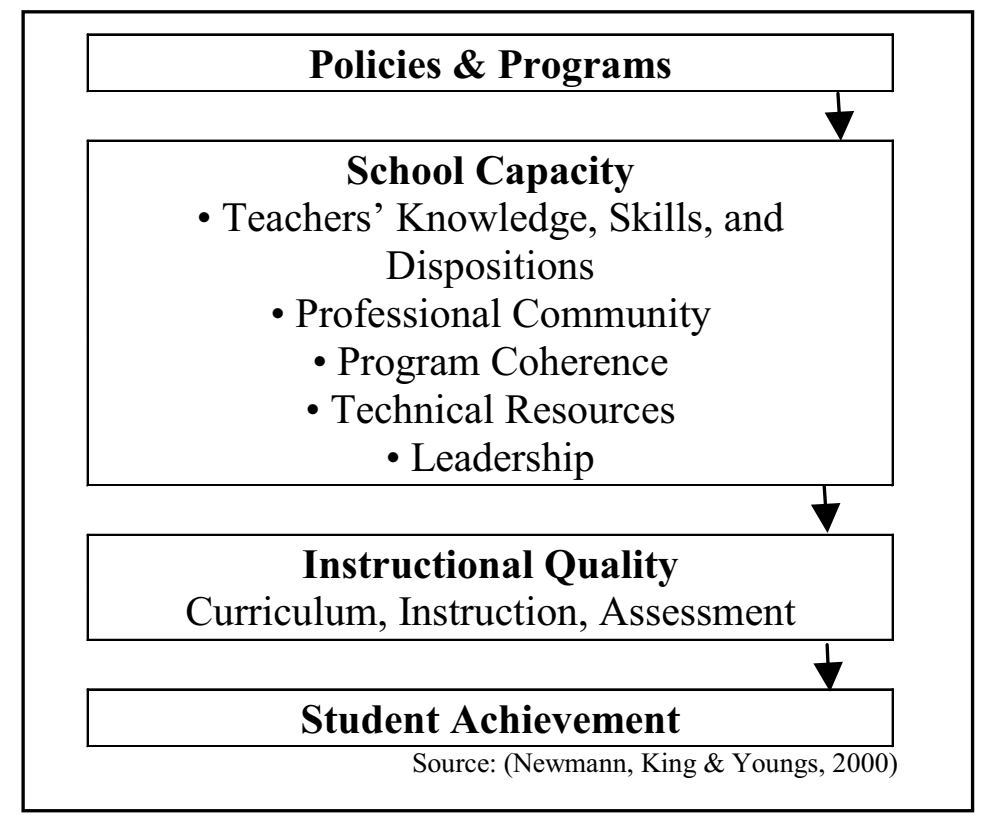

Figure 1. Policies and Programs

In our latest research in the York Region District School Board (see Mascall, Rolheiser, Wallace, Anderson, \& Fullan, 2005), we found that three elements continued to come into the foreground. These were the elements of Instructional Quality, which Newmann, King and Youngs (2000) identified as curriculum, instruction and assessment. In 
this paper, we examine the relationship between these three elements, with a particular focus on the role of assessment in strengthening school and district capacity. This analysis leads us to the development of a new model, focusing on the relationship amongst these three key elements, in what we term 'pedagogical synergy.'

\section{The York Region District School Board}

YRDSB serves over 115,000 students north of Toronto in 167 schools: 27 of which are secondary and 140 elementary. The number of elementary students has grown $4.8 \%$ per year in the five years since 2001. Forty new schools have been opened since 2000 , and the school District has announced that it will open more new schools in the next few years to meet the demands of a growing population. A number of existing elementary schools are filled to capacity. This rapidly growing District serves a diverse socio-cultural and linguistic population, with over 100 languages spoken in the schools. There are 8,811 teachers in the system. Many district-wide initiatives are in place in the YRDSB, three of which are described here. The first of these programs, the Assessment Training Program (ATP), is a comprehensive initiative established in 1998. The goal is to build understandings about effective diagnostic, formative, and summative assessment practices, and to promote interpretation of these measures among teachers and administrators, enhancing assessment literacy (Sharratt \& Rolheiser, in press). Schools choosing to participate in this program send an administrative/teacher team to a number of District training and follow-up sessions during the year. This Program is credited with creating the groundwork for the effective use of assessment across the YRDSB.

The Ontario Ministry of Education has directed all school districts to select assessment tools for use in their schools. YRDSB had identified a number of specific assessment tools to be used at particular levels in the system. The tools used in elementary schools to assess literacy include PM Benchmarks, the Developmental Reading Assessment (DRA), and Running Records. In addition to these District-wide assessment tools, the EQAO (provincial standardized 
test) results provide grade 3 and 6 Reading, Writing, and Mathematics scores for every elementary school across the province. Overall, teachers and principals are now responsible for submitting data gathered by these assessments to the District on a regular basis, while the District assumes responsibility for analyzing and reporting such data.

The concept of assessment literacy is being promoted not just within the ATP, but in all District work. This initiative establishes both comfort in the use of a range of assessment tools and techniques, and an ability to understand and interpret data, using evidence to guide decisions about practice (Stiggins, 1995.

The second of the District initiatives, Instructional Intelligence (II), began with a group of administrators in 2000; over time, however, school teams consisting of administrators and teachers volunteered to work together on this initiative. The intent of the District was to support teachers in becoming more consciously skilled in using instructional approaches that have a strong research base in terms of their impact on student achievement (Bennett \& Rolheiser, 2001). As noted by Sharratt and Rolheiser (in press), "This focus on instruction created greater coherence and connection to our work in assessment literacy... and became a very important stepping-stone for us on our journey to improvement” (p.9). The II initiative included training institutes and demonstration lessons, and follow-up sessions and support provided by the curriculum coordinator and consultant team. Over time teacher leaders have undertaken this important work and contributed to the spread of the instructional ideas (Bennett, Sharratt $\&$ Sangster, 2003). Other factors that have also contributed to the sustaining of II work six years later include: a Steering Committee (with multiple stakeholder representation); two OISE/UT preservice cohorts (elementary and secondary) that are located in YRDSB schools; graduate student II research; and, professional development activities specifically focused on developing the instructional leadership of school administrators.

Although early literacy pilot work began in 1999 in YRDSB, it has only been since 2002 that the primary goal in the YRDSB Plan for Continuous Improvement has been literacy. Since that time the District has been focusing its attention on identifying the 
challenges in improving literacy and on building the capacity in schools to make the necessary changes. The manifestation of that focus is a program called the Literacy Collaborative (LC), the third of the District initiatives we describe here. This program has evolved from a grassroots initiative in the late 1990s to what was by 2004 the major part of the activity of the Curriculum and Instructional Services Department of the District. Currently all 167 schools in the District are involved in the LC.

Under the guidance of the Literacy Collaborative each school must make a three-year commitment to provide release time for a designated Literacy Teacher (generally a 0.5 position, although some schools can allocate 0.25 time for this work). The District does not fund this position, so schools must find the necessary time within existing staff allocations. Some creative funding with Special Education Resource Teacher (SERT) positions has enabled schools to establish this position. As well, elementary schools must also commit to creating a daily two-hour literacy block for students.

Each school establishes a literacy team, comprising the Literacy Teacher, the principal, and a SERT; and, depending on whether it is an elementary or secondary school, the team may also include the Reading Recovery ${ }^{\mathrm{TM}}$ teacher, a division Lead Teacher, the ESL teacher, and perhaps a classroom teacher as well. This team attends change/leadership development days and literacy content sessions offered by the District; attendance at these sessions, which are supported by the District providing supply teachers to the school, is mandatory. These District professional development sessions for the LC are grounded in the belief that leaders across the system need to not only be skilled and knowledgeable in literacy content, but also to be skilled and knowledgeable as change leaders. There must also be a commitment by the team to collect data on the progress being made in literacy and report this progress in a yearly District culminating event, the Literacy Learning Fair. Not all of the participating schools have implemented the program fully. Some schools have a 0.25 Literacy Teacher position, due to scarce resources or the small size of the school, while others have not yet implemented the two-hour literacy block. 
In our analysis of the work of these three initiatives in the YRDSB, we have seen how each one of the three initiatives has had an impact on the other two, and that the net effect of all three has been to create stronger capacity at the school and district levels. We now present the findings from our research that led us to this realization and our new model (see Figure 2).

\section{Methodology}

For the research described here we developed case studies of four elementary schools in the YRDSB. The four school-level case studies and the cross-case analysis were a means to helping us better understand the phenomenon of capacity-building at the school level and the influence a district might have on this process (Merriam, 1998). We were looking for examples of capacity building and evidence of factors that appeared to affect how, in this case, elementary schools were able to build capacity as part of the Literacy Collaborative.

We have tracked, over two years, the evolution of school capacity in four elementary schools at different stages of implementation of the District-supported LC. This research study documents the process of evolving professional learning, describing the successes and challenges of the schools' developing capacities within the context of District-level supports. This paper is based on research conducted during the 2003-04 and 2004-05 school years. Data collection methods included conducting individual interviews, forming focus groups, videotaping professional learning experiences, and observing meetings.

\section{Findings}

We present the findings of our research on the implementation of the Literacy Collaborative under two headings: Instructional Focus, and Assessment and Evaluation. 
Pedagogical Synergy: Linking Assessment, Curriculum, and Instruction

\section{Instructional Focus}

The term 'instructional focus' has been used to direct attention on classroom practice. Elmore and Burney (1999) describe their first lesson learned from New York's District 2 as, "It is about instruction and only about instruction" (p. 239). Their research demonstrates that it is the single-minded focus on instructional practices that brings about improvement in student learning and achievement.

This focus on instruction is central to the design of the Literacy Collaborative. Sustained District-sponsored professional development has helped participants learn about the instructional practices that have the greatest impact on student learning. At the same time, the program has been working to build communities of practice in schools that share this focus on instruction and has encouraged teachers to learn from one another, creating, in effect, professional learning communities where job-embedded learning is the norm. The collaborative nature of the schools increases opportunities for all teachers to focus on quality instruction. Instructional focus has been an explicit dimension of the Literacy Collaborative from its inception.

At Ambleside Public School (pseudonyms are used for all four case schools), the instructional focus was reinforced by the modeling of school leaders. For instance, the principal, vice principal and teacher-librarian all took guided reading groups, demonstrating the importance of these practices for the staff. The sustained nature of the school's instructional focus also contributed to the strength of the instruction. It was clear that this focus developed over time, and after a number of years, inquiry and attention to quality instructional practices had become critically important to the staff of the school. Indeed, it appeared to become part of the culture of the school.

The changes at Windermere Public School were linked to the instructional leadership style of the principal over an extended period of time. She encouraged staff to be inventive and take risks in finding new ways to help students achieve at higher levels. The establishment of a common language around instruction and literacy, and a consistent approach for building strategies across grade levels, helped create coherence of programs and practices across the school. The staff recognized that the good work done in one class or grade was 
contributing to the success in later grades.

Teachers at Windermere credited the Literacy Teachers with making a significant difference to their focus on instruction, through the creation of a shared vision, the development of new knowledge and skills, and the modeling of new practices. Yet teachers acknowledged that they still had work to do; they needed to turn data collection into a continuous practice and to work with new staff to ensure that all teachers were in tune with the changing practices. There continued to be a concern, however, about sustainability of the LC in the District. As one teacher at Windermere said,

I'll be interested to see how the District continues this and embeds this in instructional practice, long term. Until it's really who you are and part of your repertoire as an instructor, it's easy to fall back on old habits when you're not too sure what to do or you don't have some form of format or structure to keep pushing everybody forward.

At Green Meadows Public School, staff and students were dealing with the move to a new school in a new community. Staff were chosen for the new school on the basis of their commitment to the importance of literacy in their teaching. This instructional focus was established from the first days of the new school. As staff came to understand how different the present student population was from the population of their previous school, they were better able to understand what it would take to address the challenges.

The staff's search for ways to redefine their classroom practice in light of the needs of their new student population required that staff spend considerable time identifying student needs and then working on strategies to meet those needs. Green Meadows staff recognized that they would need frequent and targeted data collection; in the first year of the new school, the staff met monthly in their divisions and spent time looking at charts of student achievement, with a particular emphasis on students "at risk." They started to track student reading levels on a wall chart so that all the staff could see the challenges and the progress that was being made. That action stimulated dialogue among the staff about patterns in the data and the 
differences among reading scores, EQAO tests, and DRA and PM Benchmark results. All of this data collection and dialogue had been carried out in an intentional way, based on the learning from the Literacy Collaborative.

It is important that the District's focus on instruction is concerned with actual practice. At Jefferson Public School, the development of writing exemplars galvanized the staff to work together on analyzing student work. This process brought coherence to assessment practices, as teachers reached agreement on, for example, "what a Level 3 really looks like." This collective work encouraged more of the staff to engage in the focus on literacy, as teachers collaborated on instructional planning for a grade and on providing for transitions from one grade to the next. The staff dialogue expanded to encompass instructional and assessment practices across a division and even between divisions.

It is difficult, however, for staff and leadership to sustain a focus on quality instruction in times of change. All our schools experienced such changes during our two years of research. New teachers need to be given the opportunity to learn what long-serving teachers take for granted. New leaders need to take time to learn about the culture of their new school and to find ways to introduce change that does not disrupt the good work that has already been accomplished. Given the frequent changes in leadership that seem to characterize York Region, the District is attempting to develop leadership that can accommodate this mobile workforce.

\section{Assessment and Accountability Focus}

The second area explored in our examination of the Literacy Collaborative was the focus on assessment and accountability. While many educators cringe at the word "accountability" we are using this term explicitly here as we connect it to evidence that emerges from assessment practices. Much of the focus on accountability in the YRDSB reflects an effort on the part of the District to build knowledge about assessment and to build accountability across the system by making the use of evaluation data an explicit part of every teacher's and school's practice. The use of common assessment tools, 
already part of the Assessment Training Program, is also reinforced as part of the Literacy Collaborative. The current focus of the District is on evidence-driven instruction - an attempt to encourage teachers to base their decisions about their classroom practice on the learning and achievement of their students. This practice requires frequent use of a range of assessment tools, a sophisticated interpretation of the results of these assessments, and access to a wide range of pedagogical strategies to respond to the diverse needs of children. This assessment-driven approach has become an integral part of the Literacy Collaborative, in both the change/leadership professional development sessions and in the literacy content professional development sessions with District staff.

In our case schools, all the staff had come to recognize that decisions about classroom practice were to be based on an understanding of the results of their assessment of student learning. Yet, how this played out in practice was not consistent across these schools.

At Ambleside P.S., for example, administration and staff recognized that they did not have a high level of expertise in assessment and were committed to learning more about how to analyze student achievement data. Data were needed to inform the newly prescribed school planning process. Teachers were "on the same page" about evaluation. They used a common language and a common set of approaches for assessing student achievement.

Despite the positive feelings about progress in the school, the provincial test (EQAO) scores had not improved at Ambleside; indeed, they declined somewhat in the second year of our data collection. Staff were disappointed, but started to work on understanding what these results could tell them.

Schools are challenged to manage all of the data that they collect. E-Principal (a District-wide database that gives principals access to all data about individual students) has helped with data management in YRDSB, and a District data warehouse approach is under development. However, it continues to be difficult for schools to deal with the volume of data required by the District.

Dealing with the subjectivity inherent in analyzing data is a challenge commonly identified and discussed by educators in the 
District. For example, to compare results across report cards, teachers need to be "on the same assessment page." Teachers need to know (and agree upon) what a "level 2" looks like. Provincial exemplars are used by many teachers, who also noted that they use them in explaining student achievement to parents. Jefferson P.S. was in the early stages of systematic data collection. How the data might inform teaching and learning had begun to be explored, but classroom teachers had varied levels of understanding about and comfort with analyzing and interpreting data, and with utilizing the data to inform practice. The school complied with District data collection requirements, but the results were unevenly used. There was also some difficulty in interpreting the differences between data sets - for instance, EQAO and PM Benchmarks showed quite different trends in achievement. Teachers struggled with synthesizing the information from these various sources.

Teachers and administrators at Green Meadows P.S. were turning to assessment data to help them understand their new student population. The differences between data sets merely fueled further investigation, and there was an ongoing effort to look for ways in which these data could inform instruction. Teachers and the principal actively sought to find connections and patterns between data, consistently comparing their own locally developed assessment results, the District PM Benchmark and DRA data, and the provincial EQAO findings. There appeared to be a genuine spirit of enquiry at Green Meadows, which encouraged the staff to use a variety of data sources to understand more clearly the needs of their students.

Windermere P.S. was populated with a staff of action researchers, providing evidence of the role that action research has played in YRDSB. Their conversations were filled with questions, as they explored ways to enhance student learning and contribute to enhancing the learning community. Teachers were using the language of assessment as part of these conversations. Indeed, the language was becoming part of the children's discussions as well. During a session where students were putting samples into their writing journals, one student commented to another, "I don't think that's a level 3 letter any more, I think it's a level 4." As the teacher noted, “....all that language about assessment. I wouldn't have heard that in a group a 
year ago. So it's not just at the teacher level, students are understanding their own learning." Assessment literacy at Windermere appeared to be pervasive.

The accountability at Windermere had become shared. Use of such mechanisms as student tracking boards encouraged staff conversation about the achievement levels of individual students and put faces on the data. Teachers were analyzing the data saying, "Here's a child at risk. What do we need to do? How can we tailor the instruction to meet her needs?" This shared concern produced a broader sense of accountability across the staff.

Parents on the Windermere School Council were asking for feedback on how the resources they helped provide were contributing to student achievement. Such observations were indicative of an increased level of public accountability that would not have been present even a few years earlier. The degree of comfort felt by the staff was evident in the high level of trust they showed each other. People were not trying to hide results. Rather, they presented results to each other and discussed how one might interpret the findings and what a teacher might do in light of this interpretation. Staff at Windermere expressed gratitude for the expert support they received from District personnel in managing and interpreting data. This support had made a difference in the ability of the teachers to understand what the data were saying, and to use that understanding to design future learning opportunities.

\section{Pedagogical Synergy}

We have been describing the three components of instructional quality relating to Newmann King and Youngs' (2000) model of school capacity: curriculum, instruction, and assessment. Although one might take as self-evident that these three components are essential for enhancing student achievement, in practice what often happens is that district or school initiatives related to these dimensions operate independently or compete with each other, producing either fragmentation or overload for educators.

In York Region, three programs (the Assessment Training 
Program, the Literacy Collaborative, and Instructional Intelligence) appear to have come together in the minds of educators in a complementary way, in fact, seeming to create what we have termed "pedagogical synergy". Based on our research and conceptualization, we define pedagogical synergy as a dynamic enhancement of understanding, strengthening of practice, and development of coherence. This synergy occurs when curriculum, instruction, and assessment link with and support one another, rather than operating as separate or conflicting entities.

In the early days of our previous research (Mascall, Fullan \& Rolheiser, 2001), these programs were seen as discrete and independent; and for some teachers, they were competing programs, demanding scarce resources (time, money, materials). Over the years of our research, we have noted how educators now are seeing ways these two programs fit together and support each other. In discussions about the Literacy Collaborative, teachers and principals told us of the work they were doing to improve classroom practice, informed by their work in the Assessment Training Program and Instructional Intelligence. They also spoke of how their literacy assessment has changed as a result of the Assessment Training Program. They recognized the common learning approaches and the common language associated with these programs. For example, the use of action research and other job-embedded professional development strategies have been integral aspects of all of these district-supported initiatives. Teachers clearly recognized that inquiry and continuous learning of educators was valued by the District.

This evolution has not happened in a casual way. The District has taken a strategic approach in selecting a few key foci and then targeting resources and aligning policies to ensure that these become central in the work of all educators throughout the District. In the District approach to leadership development, for example, it is clear that the expectations for administrators in the District encompass a focus on the targeted and selected District initiatives, including the Literacy Collaborative. New leaders are required to understand and support this relationship and to see it in practice in their schools.

From the perspective of our research beyond this particular study, we have been able to monitor the evolution of this strategic 
approach and have seen in our latest study that the engagement of Board members, the ongoing discussions among senior management, and the deliberate and sustained professional development with teachers and administrators have resulted in reduced fragmentation and overload among school staffs. At the same time, it has reinforced the importance of instructional quality and enhanced school capacity.

\section{A New Model}

From this research, we can see that our initial model has the right pieces: we believe we have identified key dimensions in both school capacity and district capacity. These dimensions remain the same.

However, we would suggest that putting them in boxes, in a linear order (as we did in Figure 1), suggests a vertical (hierarchical) approach to the building of capacity that we feel might be misleading. We propose a new conceptualization of our model, described in Figure 2.

Our research in York Region suggests that these items are more powerfully conceptualized horizontally, with movement back and forth between the District and the schools. Our case schools see their work as being done in collaboration with the District, with both partners clearly focused on improving the literacy results for all students. The role of the District is still pivotal in terms of setting an overall vision, providing appropriate kinds of support, and making changes in policies and procedures to align with their literacy vision. However, school teams are empowered to implement their contextually unique approaches to literacy based on the District's guidelines, and this local learning yields important insights that subsequently influence the District's ongoing work.

Desired results can occur at both the district and school levels when there are horizontal and reciprocal strategies for building capacity and increasing coherence. During the two years of our study such strategies became more evident and were more explicitly applied. With a united and coherent emphasis on curriculum (in this case, literacy as the focus), instruction, and assessment, pedagogical synergy is created. Our model describes a collaborative culture in which schools and districts support each other, rather than a counterproductive struggle to assert top-down or bottom-up ownership. 


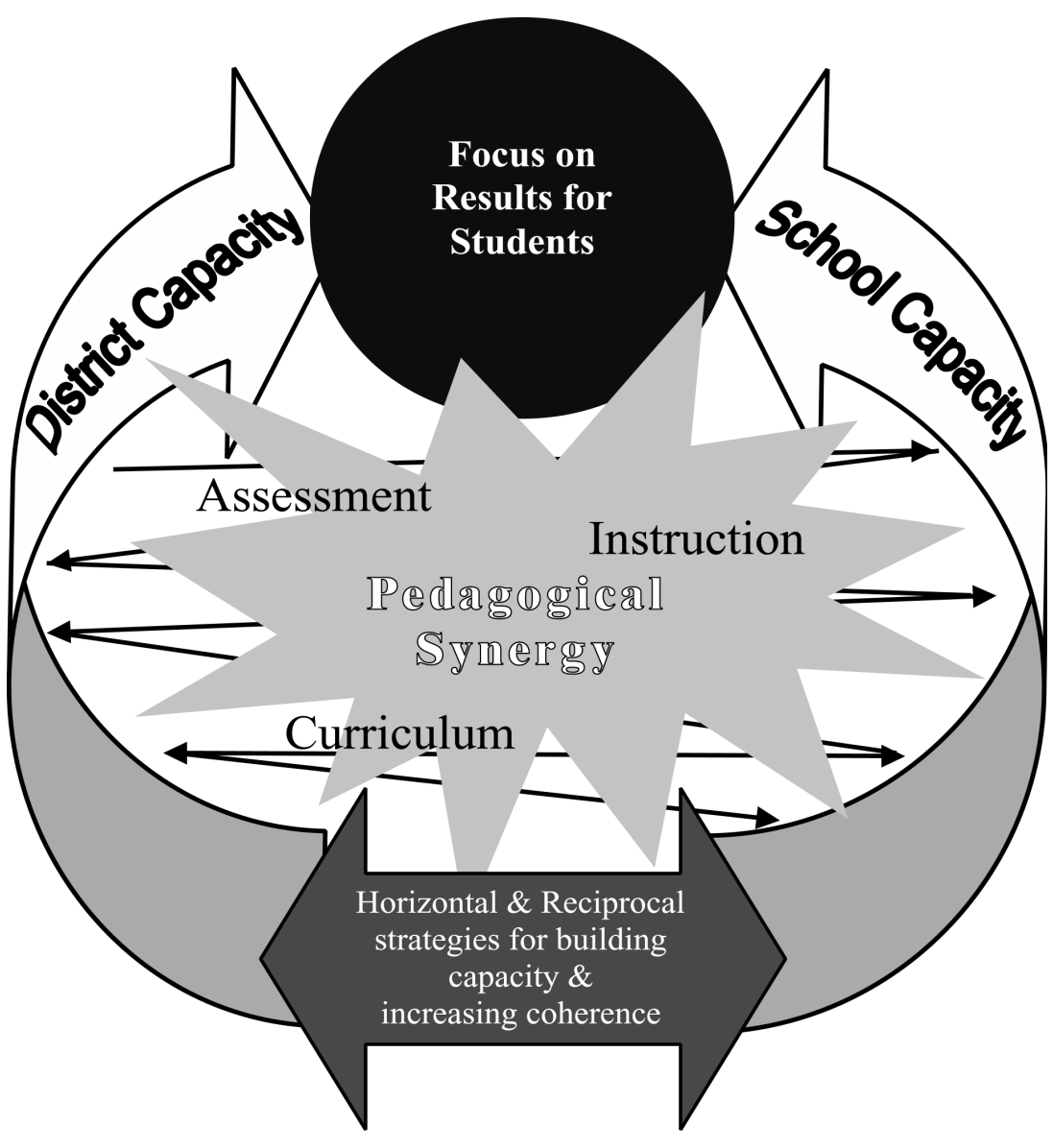

Figure 2. Pedagogical Synergy

Schools and the district are united in a focus on results for students. The reciprocal nature of the work in York Region means that vision and direction provided by the District influences school actions, while school actions and insights also influence subsequent District understandings and actions. This continuous flow of strategies builds synergy over time as curriculum, instruction and assessment become more highly integrated. The result is greater system-wide capacity, and a coherence in teaching and learning which supports both district 
and school educators.

This new model stresses the interconnectedness of the variables (they all seem to influence each other), and the horizontal (non-hierarchical) nature of the relationships among the educators. It describes an approach to education that has resulted in greater coherence across the system.

We see the experience and growth of York Region over the two years of our research as positive outcomes. Recent research by the District (Sharratt \& Fullan, in press) concludes that schools which are dedicated to implementing the Literacy Collaborative model fully over time can be expected to out-perform schools that are not. Evidence also indicates that over $80 \%$ of Grade one students in YRDSB are reading with fluency and comprehension at Level 16 (the District standard), an increase from 51\% when the Director of YRDSB first made his commitment to a literacy focus in 1998 (Sharratt \& Fullan, in press). As well, other research (Sharratt \& Rolheiser, in press) indicates that the strategic work of the District is resulting in important gains in student learning over time. The successful EQAO (the provincial standardized test) results in literacy and mathematics over the last five years are attributable, at least in part, to the strategic work of the District and the focus on and weaving together of sound assessment and instructional practices (Sharratt \& Rolheiser, in press). Certainly the evidence we saw in our case schools about building collective capacity would support such findings.

It will be important for York Region to sustain its efforts and remain focused on knowledge building about literacy. The pressure to address competing issues will be hard to resist, but we believe this model needs to be supported for the long term. In the evolution of the work in York Region to build capacity between districts, the District may worry that it will lose the strength of the internal focus it has cultivated. The staff should guard against overload and the distractions of competing policies and demands. The recent lateral shift to support work between districts is important outreach and has the potential to contribute to knowledge sharing; however, it will be important to simultaneously sustain the internal focus and energy that was evident in York Region schools during our research. 
Pedagogical Synergy: Linking Assessment, Curriculum, and Instruction

\section{References}

Bennett, B. \& Rolheiser, C. (2001). Beyond Monet: The artful science of instructional integration. Toronto, ON: Bookation.

Bennett, B., Sharratt L., \& Sangster S. (2003). A focus on Instructional Intelligence...one and one-half years into a fiveyear journey. Paper presented at meeting of ICSEI, Sydney, Australia.

Elmore, R. and Burney, D. (1999). Investing in teaching learning, in L. Darling-Hammond and G. Sykes (eds), Teaching as a Learning Profession, San Francisco, Jossey-Bass, pp. 236-91.

Mascall, B., Rolheiser, C., Wallace, D., Anderson, C., \& Fullan, M. (September 2005). Reciprocal strategies for building district and school capacity. Final report to the Ontario Ministry of Education. Toronto, ON: Ontario Institute for Studies in Education of the University of Toronto.

Mascall, B., Fullan, M., and Rolheiser, C. (2001). The challenges of coherence and capacity. Toronto, ON: Ontario Institute for Studies in Education of the University of Toronto.

Merriam, S. (1998). Case study research in education: A qualitative approach. San Francisco: Jossey-Bass.

Newmann, F., King, B., \& Youngs, P. (2000). Professional development that addresses school capacity: Lessons from urban elementary schools. American Journal of Education, 108, 259-99.

Rolheiser, C., Mascall, B., Edge, K., Bower, B. and Fullan, M. (2004). Districts going to scale: Case studies of two districts building school capacity in the implementation of early literacy strategies. Final report to the Ontario Ministry of Education. Toronto, ON: Ontario Institute for Studies in Education of the University of Toronto.

Sharratt, L. \& Fullan, M. (In press, 2006). The school district that did the right things right. The Journal of School Leadership.

Sharratt, L. \& Rolheiser, C. (In press, 2006). System change and system coherence: Staying the course. Orbit.

Stiggins, R. (1995). Assessment literacy for the $21^{\text {st }}$ century. Phi Delta Kappan, 77(3), 238-45. 